\title{
Aplicação do Medical Office Survey on Patient Safety Culture: revisão integrativa
}

Application of the Medical Office Survey on Patient Safety Culture: integrative review Aplicación del Medical Office Survey on Patient Safety Culture: revisión integradora

Ana Luiza Rodrigues Inácio ${ }^{1}$ in https://orcid.orgy 0000-0001-6620-6624 Maria Cristina Soares Rodrigues² ${ }^{2}$ in ntps://orcid.org/0000-003-0206-4238

Como citar: nácio AL, Rodrigues MC. Aplicação do Medical Office Survey on Patient Safety Culture: revisão integrativa. Acta Paul Enferm. 2022;35:eAPE001222.

DOI

http://dx.doi.org/10.37689/acta-ape/2022AR01223

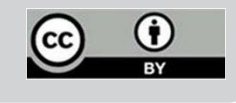

Descritores

Segurança do paciente; Cultura organizacional; Atenção primária à saúde; Qualidade da assistência à saúde; Enfermagem de atenção primária

Keywords Patient safety; Organizational culture; Primary health care; Quality indicators, health care; Primary care nursing

Descriptores

Seguridad del paciente: Cultura organizacional; Atención primaria de salud; Indicadores de calidad de la atención de salud; Enfermería de atención primaria

Submetido 28 de Maio de 2020

Aceito

21 de Junho de 202

Autor correspondente Ana Luiza Rodrigues Inácio E-mail: analuizari@ufu.br

Editor Associado (Avaliação pelos pares): Bartira de Aguiar Roza (https://orcid.org/0000-0002-6445-6846) Escola Paulista de Enfermagem, Universidade Federal de São Paulo, São Paulo, SP, Brasil

\section{Resumo}

Objetivo: Verificar como se expressa a cultura da Segurança do Paciente na visão de profissionais da Atenção Primária à Saúde, a partir da análise de produções científicas que aplicaram o instrumento Medical Office Survey on Patient Culture.

Métodos: Revisão integrativa, elaborada com base na metodologia scoping review, com busca em banco de dados online da Biblioteca Virtual em Saúde, da Web of Science, do PubMed®, do Cummulative Index to Nursing and Allied Health Literature e do Scopus, utilizando a palavra-chave "Medical Office Survey on Patient Safety Culture".

Resultados: Foram analisados 13 artigos quanto à aplicação do instrumento. Constatou-se avaliação geral positiva sobre Segurança do Paciente (32\% a 83\%). As dimensões "trabalho em equipe" e "pressão e ritmo de trabalho" foram vistas como as de melhor e pior escore, respectivamente.

Conclusão: A revisão integrativa da literatura possibilitou a análise crítica de estudos que demonstram a visão dos profissionais de saúde de diferentes países, ao avaliarem dimensões de cultura de Segurança do Paciente conforme 0 instrumento aplicado, indicando áreas consideradas positivas, bem como aquelas que demandam maior atenção e valorização. Tais evidências contribuem para o avanço na compreensão do multifacetado fenômeno investigado nos diversos ambientes da Atenção Primária.

\section{Abstract}

Objective: To assess how the Patient Safety culture is expressed in the view of Primary Health Care professionals, based on the analysis of scientific productions in which the Medical Office Survey on Patient Culture instrument was applied.

Methods: Integrative review based on the scoping review methodology with search in online databases of the Virtual Health Library, Web of Science, PubMed ${ }^{\circledR}$, Cumulative Index to Nursing and Allied Health Literature and Scopus using the keyword "Medical Office Survey on Patient Safety Culture".

Results: Thirteen articles were analyzed in relation to the application of the instrument. There was a positive overall assessment of Patient Safety (32\%-83\%). The "teamwork" and "work pressure and pace" dimensions were seen as the best and worst scores, respectively.

Conclusion: The integrative literature review allowed the critical analysis of studies that showed the view of health professionals from different countries when evaluating dimensions of the Patient Safety culture according to the instrument applied, indicating areas considered as positive, and those demanding greater attention and appreciation. Such evidence contributes to advance the understanding of the multifaceted phenomenon investigated in different Primary Care settings.

'Universidade de Brasília, Brasilia, DF, Brasil.

Conflitos de interesse: 0 presente artigo é parte de uma Tese de Doutorado a ser apresentada ao Programa de Pós-Graduação em Enfermagem (PPGEnf) da Universidade de Brasília (UnB). 


\section{Resumen}

Objetivo: Verificar cómo se expresa la cultura de la Seguridad del Paciente bajo la mirada de profesionales de la Atención Primaria en Salud, a partir del análisis de producciones científicas que aplicaron el instrumento Medical Office Survey on Patient Culture.

Métodos: Revisión integradora, elaborada con base en la metodología scoping review y búsqueda en banco de datos en línea de la Biblioteca Virtual de Salud, de la Web of Science, de PubMed®, del Cummulative Index to Nursing and Allied Health Literature y de Scopus, utilizando la palabra clave "Medical Office Survey on Patient Safety Culture".

Resultados: Se analizaron 13 artículos con relación a la aplicación del instrumento. Se constató una evaluación general positiva sobre la Seguridad del Paciente (32 \% a 83 \%). Las dimensiones "trabajo en equipo" y "presión y ritmo de trabajo" fueron las que tuvieron mejor y peor puntuación, respectivamente.

Conclusión: La revisión integradora de la literatura posibilitó el análisis crítico de estudios que demuestran la visión de los profesionales de salud de distintos países, al evaluar las dimensiones de la cultura de la Seguridad del Paciente de acuerdo con el instrumento aplicado, indicando áreas consideradas positivas, así como las que demandan más atención y valorización. Esas evidencias contribuyen para el avance de la comprensión del multifacético fenómeno investigado en los diversos ambientes de la Atención Primaria.

\section{Introdução}

A Segurança do Paciente é conceituada como a redução do risco de danos considerados desnecessários a um mínimo aceitável na assistência, sendo apontada como dimensão primordial para a qualidade em saúde. ${ }^{(1)}$ Avaliar a percepção dos profissionais acerca da cultura de Segurança do Paciente na Atenção Primária à Saúde também surge como parâmetro importante na identificação dos domínios e variáveis que necessitam de atenção, por meio de diagnóstico situacional individualizado, possibilitando que estratégias sejam traçadas para a efetivação do cuidado seguro na rede de atenção. ${ }^{(2)}$

Questôes associadas à Segurança do Paciente apresentam-se como uma questão de saúde pública, uma vez que têm aumentado os riscos e os incidentes que provocam danos aos pacientes. ${ }^{(3,4)}$ Muito se faz na tentativa de compreender as causas e as consequências dos erros em saúde, principalmente no ambiente hospitalar, a fim de propor soluçôes adequadas. ${ }^{(5,6)}$ No entanto, ocorrências de erros também estão presentes no contexto da Atenção Primária à Saúde e ainda são pouco discutidos. Desse modo, proporcionar uma cultura de segurança construtiva, com estabelecimento de valores compartilhados e comportamentos seguros na prática diária do cuidado, torna-se essencial para o aprimoramento da Segurança do Paciente em ambientes extra-hospitalares. ${ }^{(7)}$

O instrumento Medical Office Survey on Patient Safety Culture (MOSPSC), desenvolvido pela Agency for Healthcare Research and Quality (AHRQ), dos Estados Unidos, em 2007, enfatiza questóes relacionadas à Segurança do Paciente e à qualidade do cuidado prestado nos serviços de cuidados primários. $\mathrm{O}$ instrumento original é constituído de 51 perguntas que medem 12 dimensóes, incluindo sessóes sobre questôes relacionadas à segurança do paciente e qualidade, à comunicação, ao processo de trabalho, à aprendizagem e ao treinamento. A AHRQ recomenda, para tratamento e análise dos dados do instrumento, a avaliação da porcentagem de respostas positivas quanto à cultura de Segurança do Paciente, em que, em média, o percentual de respostas positivas deve alcançar $50 \%$ ou mais para se apontar que a cultura de Segurança do Paciente é positiva naquele ambiente. ${ }^{(8)}$

O instrumento MOSPSC foi testado em mais de 200 serviços de saúde dos Estados Unidos, com mais de 4.100 pesquisas respondidas, em que os pesquisadores examinaram a confiabilidade e a estrutura fatorial dos compostos de cultura de segurança, de modo que os itens e as dimensóes finais foram considerados com propriedades psicométricas sólidas. ${ }^{(9)}$

Tal instrumento possibilita a análise do status atual da cultura de Segurança do Paciente, estimulando a consciência acerca dela. $\mathrm{O}$ instrumento MOSPSC auxilia na identificação de pontos fortes e daqueles que necessitam de melhorias, permite a análise de tendências na mudança de cultura de Segurança do Paciente ao longo do tempo, verifica o impacto cultural das iniciativas e intervençóes de Segurança do Paciente e permite comparaçóes dentro e entre organizaçóes. ${ }^{(5)}$ Trata-se de um instrumento versátil, que já foi traduzido e adaptado para diferentes línguas, sendo utilizado pelo mundo em ambientes de saúde no âmbito dos cuidados primários, em países como México, Espanha, Brasil, 
Iêmen, Catar, Polônia e Portugal. ${ }^{(6,10-15)}$ No entanto, o assunto requer explorar evidências produzidas.

Assim, o desenvolvimento de uma revisão sobre o tema possibilita conhecer e/ou reconhecer estudos que estão sendo realizados no Brasil e no mundo, trazendo à luz fragilidades e fortalezas identificadas acerca da Segurança do Paciente em ambientes de cuidados primários e, por outro lado, apontar as oportunidades de novas pesquisas na área. Logo, é necessário examinar o tópico "cultura de segurança" na perspectiva das equipes multiprofissionais (a visão do profissional sobre o assunto) para, então, gerar um corpo de conhecimento e, consequentemente, provocar reflexóes, questionamentos e debates que possam contribuir para o avanço da questão em foco, no intuito de promover melhorias na qualidade da assistência na Atenção Primária à Saúde, com uma cultura sólida de Segurança do Paciente nos serviços.

O objetivo deste estudo foi verificar como se expressa a cultura da Segurança do Paciente na visão dos profissionais da Atenção Primária à Saúde, a partir da análise de produçóes científicas que aplicaram o instrumento MOSPSC.

\section{Métodos}

Trata-se de revisão integrativa, elaborada com base na metodologia scoping review (análise de escopo) recomendada pelo Instituto Joanna Briggs, com a seleçáo de artigos publicados que utilizaram o MOSPSC. A técnica de scoping review tem por finalidade sintetizar e disseminar o estado da arte em uma área temática, por meio de um método rigoroso e transparente. ${ }^{(16)}$ Foram percorridas as seguintes etapas: identificação da temática; definição da questão norteadora; delimitação de critérios de inclusão e exclusão de estudos; definição das informações a serem extraídas dos estudos selecionados; avaliação dos estudos incluídos e interpretação dos resultados. ${ }^{(17)}$

Para elaboração da pergunta norteadora, aplicou-se a estratégia PICO, com "P" correspondendo à população (percepção dos profissionais que atuam na Atenção Primária à Saúde), "I" à intervenção (aplicação do MOSPSC), “C” à comparação (não se aplica, pois esse náo é um estudo comparativo) e "O" ao desfecho (expressáo da cultura de Segurança do Paciente). Emergiu, assim, a seguinte questão de pesquisa: Como se expressa a cultura de Segurança do Paciente na percepção dos profissionais que atuam na Atenção Primária à Saúde quando aplicado o instrumento MOSPSC?

Realizou-se busca nos bancos de dados online da Biblioteca Virtual em Saúde, Web of Science, PubMed $^{\circledR}$, Cumulative Index to Nursing and Allied Health Literature (CINAHL) e Scopus, no mês de janeiro de 2020, utilizando-se a palavra-chave "Medical Office Survey on Patient Safety Culture". Os processos de busca e seleção dos estudos foram feitos por dois pesquisadores, de forma independente. Estabeleceram-se como critérios de inclusão: apenas artigos; publicados a partir do ano de 2008 (ano seguinte à criação do instrumento); em qualquer idioma; pesquisas que utilizaram o MOSPSC, com objetivo geral de avaliaçáo inicial da cultura de Segurança do Paciente em ambientes de cuidados primários em saúde. Foram excluídos: teses, livros, dissertaçóes; publicaçóes que não utilizaram o MOSPSC, ou que o utilizaram, mas com objetivo diferente do exposto e publicaçóes duplicadas.

Após a seleção das publicações, utilizou-se o gerenciador de referências Endnote Web, para armazenamento e organização dos estudos. Em seguida, foi elaborada uma tabela contendo a referência ao artigo, o local do estudo e a caracterização da amostra, além de ter sido construído um fluxograma Preferred Reporting Items for Systematic Reviews and Meta-Analyses (PRISMA). ${ }^{(18)}$

\section{Resultados}

A figura 1 apresenta o processo que levou à seleção dos 13 artigos para a revisão integrativa. A caracterização dos estudos selecionados, segundo variáveis de interesse, está representada no quadro 1.

As recomendações do instrumento original ${ }^{(8)}$ para análise descritiva dos dados sugerem o cálculo 


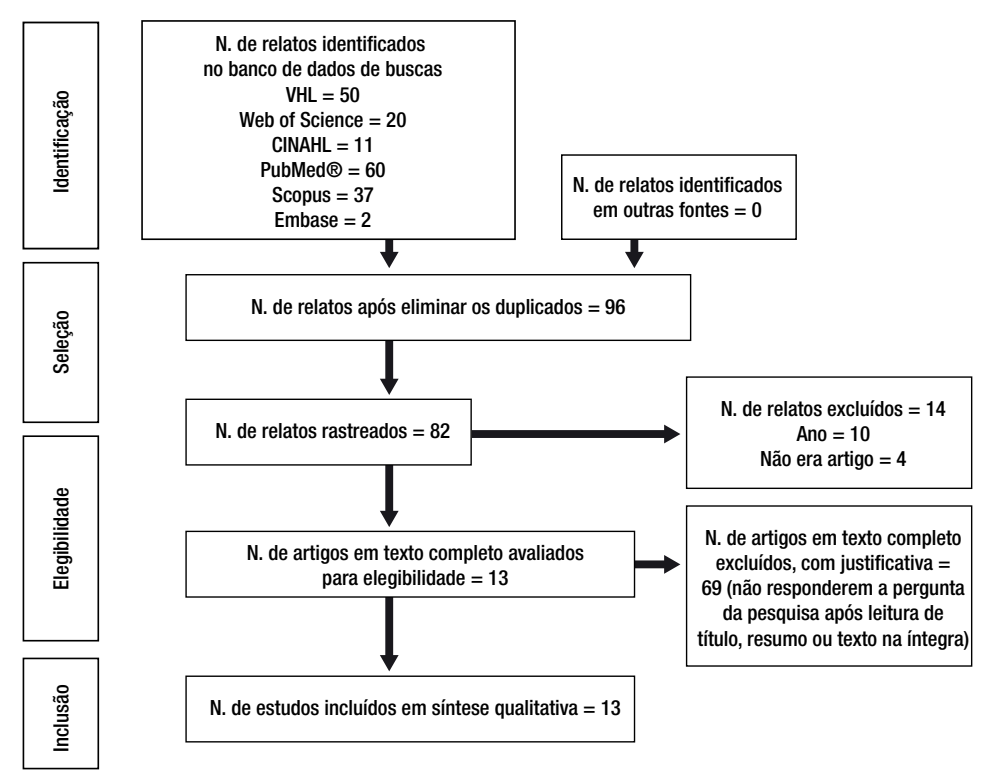

BVS - Biblioteca Virtual em Saúde; CINAHL - Cumulative Index to Nursing and Allied Health Literature

Figura 1. Fluxograma da seleção dos estudos

Quadro 1. Caracterização dos estudos selecionados, segundo variáveis de interesse

\begin{tabular}{|c|c|c|}
\hline Referência & Local & Amostra \\
\hline Flores-González et al.(10) & Villahermos & 164 profissionais \\
\hline Astier-Peña et al. ${ }^{(11)}$ & Espanha & 215 centros e 4.344 profissionais \\
\hline Webair et al. ${ }^{(13)}$ & lêmen & 16 centros e 78 profissionais \\
\hline El Zoghbi et al..$^{(14)}$ & Catar & $\begin{array}{l}21 \text { centros e } 1.810 \text { profissionais em } 2012 \\
2.616 \text { profissionais em } 2015\end{array}$ \\
\hline Raczkiewicz et al.(15) & Polônia & $\begin{array}{l}\text { Todos os centros de saúde da Polônia, } 337 \\
\text { profissionais }\end{array}$ \\
\hline Hagopian et al..$^{(19)}$ & $\begin{array}{l}\text { Cleveland, } \\
\text { Estados Unidos }\end{array}$ & 180 centros e 387 profissionais \\
\hline Mazurenko et al.(20) & Estados Unidos & 846 centros e 19.848 profissionais \\
\hline Hickner et al. ${ }^{(21)}$ & Estados Unidos & - \\
\hline Pohlman et al.(22) & Estados Unidos & 236 profissionais \\
\hline Romero et al. ${ }^{(23)}$ & \begin{tabular}{|l|} 
Galícia, \\
Espanha \\
\end{tabular} & 182 profissionais \\
\hline Yansane et al. ${ }^{(24)}$ & Estados Unidos & $\begin{array}{l}4 \text { instituições odontológicas e } 1.615 \\
\text { profissionais }\end{array}$ \\
\hline Macedo et al. ${ }^{(25)}$ & Londrina, Brasil & 513 profissionais \\
\hline Ramoni et al.(26) & Estados Unidos & 328 profissionais \\
\hline
\end{tabular}

da frequência de respostas de cada item e a média para cada dimensão da seguinte forma: classificadas como fortes quando $75 \%$ ou mais dos participantes respondem concordo "totalmente/concordo" ou "frequentemente/sempre" para as perguntas formuladas positivamente; e "discordo totalmente/discordo" ou "nunca/raramente" para as perguntas formuladas negativamente. Por sua vez, são classificadas como fracas quando $50 \%$ ou mais dos participantes respondem negativamente, optando por "discordo totalmente/ discordo" ou "nunca/raramente" para perguntas for- muladas positivamente, ou usando "concordo totalmente/concordo", "sempre/frequentemente" para perguntas formuladas negativamente.

Dos 13 artigos selecionados para a revisão, seis basearam-se nas recomendaçōes da AHRQ para análise e tratamentos dos dados, sendo que, para o cálculo das porcentagens positivas, o escore de cada dimensão é calculado por meio da média do percentual das respostas de cada item. Dessa forma, resultou em: El Zoghbi et al. ${ }^{(14)}$ (catariano) com $80 \%$ como parâmetro para "ponto forte" e 60\% "ponto fraco"; Webair et al et al. ${ }^{(13)}$ (iemenita) com 75\% como parâmetro para "ponto forte" e 60\% "ponto fraco"; Mazurenko et al. ${ }^{(20)}$ (norte-americano), Romero et al. ${ }^{(23)}$ (galiciano), Macedo et al. ${ }^{(25)}$ (brasileiro) e Flores-González et al. ${ }^{(10)}$ (mexicano) com $75 \%$ como parâmetro para "ponto forte" e $50 \%$ para "ponto fraco". Assim, em relação à Segurança do Paciente, a avaliaçáo geral positiva (muito bom e excelente), quando avaliada, variou entre $32 \%$ e $83 \%$ entre os participantes das pesquisas (Tabela 1).

Dentre os 11 trabalhos que apresentaram a média de avaliaçáo geral de Segurança do Paciente, sete deles (um catariano, um polonês, um galiciano e quatro norte-americanos $)^{(14,15,19,22-24,26)}$ apresentaram percentuais de respostas positivas de $50 \%$ ou mais, demonstrando que a cultura de Segurança do Paciente é positiva 
Tabela 1. Avaliação geral positiva, nos artigos analisados

\begin{tabular}{|c|c|}
\hline Referência & $\%$ \\
\hline Flores-González et al. ${ }^{(10)}$ & 19 e $45^{\star}$ \\
\hline Astier-Peña et al..$^{(11)}$ & $34 \dagger$ \\
\hline Webair et al. ${ }^{(13)}$ & 46 \\
\hline El Zoghbi et al..(14) & 43 e $62 \ddagger$ \\
\hline Raczkiewicz et al. ${ }^{(15)}$ & 61 e $39 \S$ \\
\hline Hagopian et al. ${ }^{(19)}$ & 67 \\
\hline Pohlman et al. ${ }^{(22)}$ & 83 \\
\hline Romero et al. ${ }^{(23)}$ & 72 \\
\hline Yansane et al. ${ }^{(24)}$ & 78 \\
\hline Macedo et al. ${ }^{(25)}$ & 35 \\
\hline Ramoni et al. ${ }^{26)}$ & 65 e $48 \eta$ \\
\hline
\end{tabular}

*Respectivamente, valores para "bom" e "muito bom"; † média geral - "muito bom" e "excelente"; † respectivamente, valores para os anos 2012 e 2015; § Respectivamente, valores para "muito bom" e "excelente"; ๆ respectivamente, valores para equipe médica e odontológica.

naqueles ambientes. Mazurenko et al. ${ }^{(20)}$ e Hickner et al. ${ }^{(21)}$ apresentaram comparaçóes entre as diferentes categorias profissionais sobre as avaliaçóes gerais de Segurança do Paciente, sem apresentar média geral. Os percentuais de escores positivos e negativos dos itens do MOSPSC são apresentados no quadro 2.

Quadro 2. Escores positivos e negativos dos itens do Medical Office Survey on Patient Safety Culture, nos artigos analisados

\begin{tabular}{|c|c|c|c|c|}
\hline \multirow{2}{*}{ Referência } & \multicolumn{4}{|c|}{ Itens } \\
\hline & Com escore positivo & $\%$ & com escore negativo & $\%$ \\
\hline \multirow{3}{*}{$\begin{array}{l}\text { Flores-González } \\
\text { et al. }{ }^{(10)}\end{array}$} & Trabalho em equipe & 65 & Pressão e ritmo de trabalho & 29 \\
\hline & \multirow[t]{2}{*}{$\begin{array}{c}\text { Monitoramento de } \\
\text { cuidados com o paciente }\end{array}$} & \multirow[t]{2}{*}{63} & $\begin{array}{c}\text { Comunicação e capacidade } \\
\text { de resposta }\end{array}$ & 30 \\
\hline & & & $\begin{array}{l}\text { Apoio de gestão para a } \\
\text { Segurança do Paciente }\end{array}$ & 30 \\
\hline $\begin{array}{l}\text { Astier-Peña et } \\
\text { al. }{ }^{(11)}\end{array}$ & $\begin{array}{l}\text { Segurança do paciente e } \\
\text { questões de qualidade }\end{array}$ & - & Pressão e ritmo de trabalho & - \\
\hline Webair et al. ${ }^{(13)}$ & Trabalho em equipe & 96 & Pressão e ritmo de trabalho & 57 \\
\hline 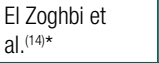 & Trabalho em equipe & 87 & Pressão de trabalho & - \\
\hline $\begin{array}{l}\text { Hagopian et } \\
\text { al. }^{(19)}\end{array}$ & $\begin{array}{c}\text { Rastreamento/ } \\
\text { acompanhamento dos } \\
\text { cuidados com o paciente }\end{array}$ & 80 & Abertura de comunicação & - \\
\hline Hickner et al.(21) & Trabalho em equipe & - & Pressão no trabalho & - \\
\hline Pohlman et al. ${ }^{(22)}$ & Trabalho em equipe & 90 & - & - \\
\hline \multirow[t]{3}{*}{ Romero et al. ${ }^{.(23)}$} & $\begin{array}{l}\text { Aprendizagem } \\
\text { organizacional }\end{array}$ & 79 & $\begin{array}{c}\text { Aspectos relacionados com } \\
\text { a segurança do paciente e a } \\
\text { qualidade }\end{array}$ & 46 \\
\hline & \multirow[t]{2}{*}{ Trabalho em equipe } & \multirow[t]{2}{*}{75} & $\begin{array}{l}\text { Troca de informações com } \\
\text { outros dispositivos de } \\
\text { cuidado }\end{array}$ & 45 \\
\hline & & & Ritmo e carga de trabalho & 31 \\
\hline \multirow[t]{2}{*}{ Yansane et al. ${ }^{(24)}$} & $\begin{array}{l}\text { Aprendizado } \\
\text { organizacional }\end{array}$ & 85 & \multirow[t]{2}{*}{ Pressão de trabalho e ritmo } & - \\
\hline & Trabalho em equipe & 79 & & \\
\hline Macedo et al. ${ }^{(25)}$ & - & - & Suporte da liderança & 47 \\
\hline Ramoni et al. (26) & Trabalho em equipe & 72 & - & - \\
\hline
\end{tabular}

*Melhores escores: dados da pesquisa de 2015, pois, em 2012, não houve dimensões com percentuais acima de $80 \%$; piores escores: dados das pesquisas de 2012 e 2015 iguais

A dimensão "trabalho em equipe" foi a melhor percebida, sendo citada em nove dos 13 trabalhos avaliados", ${ }^{(10,13,14,19,21-24,26)}$ seguida das dimensôes "aprendizagem organizacional" $(13,14,23,24)$ e "rastreamento/ acompanhamento do cuidado ao paciente". ${ }^{(10,14)}$ Por outro lado, a dimensão "pressão e ritmo de trabalho" apareceu na maioria do trabalhos, ${ }^{(10,11,13,14,19,21,23,24)}$ sendo apontada como a de pior escore na avaliação da Segurança do Paciente. Alguns artigos também destacaram a diferença nos escores de profissionais com responsabilidades gerenciais, nos quais a percepção é melhor, quando comparada aos demais profissionais, ${ }^{(11,20,21,26)}$ em que líderes têm probabilidade $40 \%$ maior de avaliar uma percepção positiva. ${ }^{(11)}$ Além disso, vale destacar que o parâmetro "suporte da liderança” foi apontado em três artigos como uma das sessóes que recebeu pior escore. ${ }^{(20,22-24)}$

\section{Discussão}

Para tratamento e análise dos dados do instrumento, a AHRQ recomenda a avaliação da porcentagem de respostas positivas quanto à cultura de Segurança do Paciente. Em média, o percentual de respostas positivas deve alcançar $50 \%$ ou mais para se apontar que a cultura de Segurança do Paciente é positiva naquele ambiente. Para o cálculo das porcentagens positivas, as sessóes são avaliadas de diferentes maneiras, sendo o escore de cada dimensão calculado por meio da média do percentual das respostas de cada item, por dimensão. ${ }^{(8)}$

Apesar da relevância e das traduçôes já realizadas para diferentes línguas, ainda há poucas evidências de aplicação do MOSPSC no Brasil quando se busca avaliar a cultura de Segurança do Paciente na APS. Vale destacar aqui alguns estudos que utilizaram o instrumento MOSPSC, mas não foram encontrados na busca de dados realizada nas bases de dados. Estudo realizado na cidade de Curitiba, no ano de 2017 , com o objetivo de avaliar a cultura de Segurança do Paciente sob a perspectiva dos enfermeiros na APS apontou cultura de segurança positiva $(73,9 \%$ "bom" e $50 \%$ "muito bom"). (27) Outra pesquisa também realizada na região sul brasileira, no mesmo ano, objetivando comparar a cultura de Segurança do Paciente entre as categorias profissionais atuantes na APS, apresentou média geral de respostas positivas entre profissionais enfermeiros $(67,70 \%)$, auxiliares/ técnicos de enfermagem $(62,84 \%)$, auxiliares/técni- 
cos de saúde bucal (59,46\%), dentistas (58,06\%) e médicos $(51,79 \%)$. Ao contrário, apenas os Agentes Comunitários de Saúde apresentaram uma cultura de Segurança do Paciente desfavorável $(46,73 \%$ de respostas positivas). ${ }^{(28)}$

Pesquisas feitas em âmbito internacional, como, por exemplo, um estudo realizado na Turquia, que utilizou um questionário sobre a cultura de Segurança do Paciente no contexto hospitalar, porém aplicado com profissionais atuantes nos espaços assistenciais da Atenção Básica, identificaram a cultura positiva de Segurança do Paciente em apenas 46\% dos profissionais, apresentando percentual baixo e negativo. ${ }^{(29)}$ Já no estudo iraniano, com a utilização de uma versão modificada de um questionário da área hospitalar sobre cultura de Segurança do Paciente com profissionais dos centros de saúde da Atenção Básica, identificou que a cultura de segurança se apresentava positiva em $57 \%$ dos profissionais. ${ }^{(30)}$

Investigação norte-americana, que buscou avaliar a associação entre cultura de segurança e medidas de qualidade em unidades de atendimento, concluiu que, embora a teoria da segurança preveja uma associação positiva entre cultura de segurança e qualidade, não se encontraram associaçóes significativas entre a primeira e medidas atualmente aceitas para a qualidade clínica na Atenção Básica. Ainda, argumenta-se que, sendo a cultura de segurança um construto tão complexo, medi-lo com precisão requer o uso de métodos/dados qualitativos, como entrevistas individuais, apontando, por fim, que poderia a cultura de segurança ser algo táo distante no processo de cuidados de resultados reais que as duas entidades não estão relacionadas. ${ }^{(19)}$

$\mathrm{O}$ instrumento MOSPSC também permite a identificação de dimensôes consideradas "pontos fortes" da cultura de Segurança do Paciente, com o percentual de respostas positivas igual ou superior a $75 \%$ e como "pontos fracos" nos casos em que os percentuais de respostas positivas forem inferiores a $50 \%$. Dessa forma, é possível identificar as áreas que necessitam de melhorias. ${ }^{(8)}$

Como a dimenssão "pressão de trabalho e ritmo" foi apontada como a de pior escore, quase unanimamente entre as pesquisas levantadas, sugere-se que seria possível trabalhar na redução desse parâmetro revendo e melhorando os processos nas diferentes áreas e serviços. ${ }^{(7,12,31)}$
O estudo iemenita ${ }^{(13)}$ destaca a falta de tecnologias adequadas ou suficientes, inadequação de pessoal e provedores para lidar com a carga do paciente e deficiência de ritmo de trabalho como justificativas para a ococrrência de erros, e, ao mesmo tempo, como áreas para melhoria. Para atendimento, demanda e desempenho adequado das funçôes, faz-se necessário número suficiente de profissionais. Portanto, a sobrecarga pode ser apontada como reflexo da falta de investimentos na Atenção Primária à Saúde, gerando reflexóes de aspectos importantes para a Segurança do Paciente e a saúde do trabalhador. ${ }^{(7,28)}$

A pesquisa espanhola, ${ }^{(11)}$ ao apontar a dimensão "comunicação sobre erro" vista mais negativamente por médicos, por exemplo, destaca que falhas de comunicação podem contribuir para a ocorrência de muitos eventos adversos que afetam diretamente a Segurança do Paciente, o que é corroborado por outros estudos, ao apontarem a comunicação como fator contribuinte mais comum para a ocorrência de incidente na Atenção Primária à Saúde. ${ }^{(5,27,32)}$ Consequentemente, a pesquisa para melhorar o desempenho das equipes é uma das futuras açóes-chave a ser tomada, ${ }^{(14)}$ sendo que a capacidade de resposta dos centros de saúde às preferências, às necessidades e aos valores individuais do paciente é área de preocupação para gestores e profissionais de saúde. ${ }^{(10)}$

Estabelecer um clima de segurança está diretamente ligado ao estilo de liderança transformacional dos diretores executivos, em que uma liderança consciente desempenha um papel fundamental na sustentabilidade de qualquer esforço para cultura de segurança. ${ }^{(24)}$

$\mathrm{O}$ estudo norte-americano ${ }^{(21)}$ sugere que a prática de gerentes/administradores em particular precisa dar mais atenção às necessidades de treinamento do pessoal, uma vez que este era uma área com uma das maiores lacunas quanto à percepção positiva. Existe uma falta estatisticamente significativa de concordância entre membros da equipe, dependendo de suas origens e funçóes. Assim, tanto os gerentes dos serviços como os médicos precisam ser mais abertos às ideias da equipe em geral, sobre como melhorar os processos de acolhimento/ atendimento, além de incentivar a equipe a questionar e a expressar pontos de vista alternativos. ${ }^{(10,20,21)}$

Consequentemente, estimulam-se o conhecimento e o uso de sistemas de notificação de inci- 
dentes, incentivando uma atitude crítica e de autoaprendizagem. ${ }^{(23)}$ Ainda assim, é possível identificar que o modo aprendizagem a partir do erro necessita de melhorias, tendo como estratégias para sanar a lacuna referente ao conhecimento, à comunicação e à prática educativa, que melhoram a interação entre líderes e profissionais, além do combate à instituição de uma cultura do medo. ${ }^{(2)}$

No estudo realizado no Catar, as melhorias observadas acerca da Segurança do Paciente entre 2012 e 2015 foram atribuídas à implementação do programa de acreditação, bem como a inúmeras oficinas, campanhas e treinamentos que foram fornecidas pelo principal prestador de cuidados em saúde no país. ${ }^{(14)}$

Como limitação desta revisão integrativa, ressalta-se a carência de artigos relacionados ao uso de determinado instrumento, o que, talvez, torne o tema muito específico, além do fato de se verificar apenas a percepção de profissionais, excluindo-se a percepção de usuários.

Destaca-se, como contribuiçóes desta pesquisa, que a realização de novos estudos que busquem avaliar a cultura de Segurança do Paciente, na visão dos profissionais que utilizam o MOSPSC, auxiliará no aprimoramento do instrumento, podendo ter novas adaptações e ser replicável em outros ambientes de Atenção Primária à Saúde. Assim, colabora-se para a melhoria do gerenciamento de riscos e incidentes em espaços de cuidados primários, além de contribuir para a disseminação do conhecimento sobre a temática, uma vez que ainda há poucos dados disponíveis na literatura.

Quatro estudos metodológicos de tradução e adaptação cultural do instrumento de avaliação MOSPSC foram encontrados durante a busca nas bases de dados, sendo dois na Espanha, um no Brasil e um em Portugal. ${ }^{(3,12,33,34)}$ Contudo, o processo de escolha de um instrumento elaborado em língua, contexto e cultura diferentes daqueles onde se pretende utilizá-lo consiste apenas no primeiro passo de um processo maior para torná-lo confiável, válido e eficaz para aplicabilidade em outra realidade, permitindo-se, assim, a construção de uma ferramenta de medição equivalente à sua versão original. ${ }^{(35)}$

Além de tais apontamentos, para futuros estudos, chama-se a atenção para o número amostral pequeno e a pequena diversidade de categorias profissionais como possíveis limitaçóes de trabalhos a serem desenvolvidos na temática. ${ }^{(13,23,25)}$ A AHRQ orienta que a pesquisa seja elaborada para ser administrada a todos os provedores e funcionários dos estabelecimentos que oferecem atendimento de nível básico de saúde. ${ }^{(8)}$

Portanto, a disponibilidade de questionários climáticos adaptados a diferentes idiomas acerca da Segurança do Paciente permite comparaçóes entre os diversos países para conhecer/reconhecer os diferentes fatores que afetam a cultura de segurança. As experiências da validação dos questionários, resultados gerais obtidos e medidas tomadas para melhorar a segurança devem ser partilhadas, e mais pesquisas devem ser executadas. ${ }^{(12)}$

\section{Conclusão}

Os artigos selecionados e analisados nesta revisão integrativa da literatura reúnem relevantes evidências para o conhecimento do assunto em pauta. Assim, com a análise crítica dos estudos incluídos, é possível reconhecer a produção científica, bem como constatar a visão dos profissionais acerca da cultura de Segurança do Paciente na Atenção Primária à Saúde. Os resultados mostram que a cultura de Segurança do Paciente apresentou uma avaliação geral positiva (muito bom e excelente) entre os participantes das pesquisas nos serviços dos países que aplicaram o instrumento. A dimensão "trabalho em equipe" foi a melhor vista de forma geral, e, de maneira oposta, a dimensão "pressão e ritmo de trabalho" apareceu majoritariamente como a de pior escore. Esses indicadores, ao apontarem áreas que demandam maior atenção e valorização na visão dos profissionais, contribuem para o avanço na compreensão do multifacetado fenômeno da cultura de Segurança do Paciente em diferentes ambientes da Atenção Primária.

\section{Colaborações}

Inácio ALR e Rodrigues MCS contribuíram com a concepção do projeto, análise e interpretação dos dados, redação do artigo, revisão crítica relevante do conteúdo intelectual e aprovação da versão final a ser publicada. 


\section{Referências}

1. Lisboa. Organização Mundial da Saúde (OMS). Estrutura conceitual da Classificação Internacional sobre Segurança do Doente. Relatório Técnico. Lisboa: OMS; 2011 [citado 2021 Jan 7]. Disponível em: https://www.dgs.pt/documentos-e-publicacoes/classificacaointernacional-sobre-seguranca-do-doente-png.aspx

2. Galhardi NM, Roseira CE, Orlandi FS, Figueiredo RM.Assessment of the patient safety culture in primary health care. Acta Paul Enferm. 2018;31(4):409-16.

3. Eiras M, Escoval A, Silva C. Patient safety culture in Portuguese Primary Care: validation of the Portuguese Version of the Medical Office Survey. London: IntechOpen; 2018 [cited 2021 Jan 7]. Available from: https:// www.intechopen.com/books/vignettes-in-patient-safety-volume-4/ patient-safety-culture-in-portuguese-primary-care-validation-of-theportuguese-version-of-the-medica

4. Silva AC, Silva JF, Santos LR, Avelino FV, Santos AM, Pereira AF. Patient safety in the hospital context: an integrative literature review. Cogitare Enferm. 2016;21(Esp):1-9.

5. Marchon SG, Mendes Júnior WV. Patient safety in primary health care: a systematic review. Cad Saude Publica. 2014;30(9):1-21.

6. Ornelas MD, Pais D, Sousa P. Patient safety culture in Portuguese Primary Healthcare. Qual Prim Care. 2016; 24(5):214-8.

7. Souza MM, Ongaro JD, Lanes TC, Andolhe R, Kolankiewicz AC, Magnago TS. Patient safety culture in the Primary Health Care. Rev Bras Enf. 2019;72(1):32-9.

8. Sorra J, Gray L, Famolaro T, Yount N, Behm J. AHRQ medical office survey on patient safety culture: user's guide. Rockville (MD): AHRQ; 2018 [cited 2021 Jan 7]. Available from: https://www.ahrq.gov/sites/ default/files/wysiwyg/sops/surveys/medical-office/medical-officesurvey-userguide.pdf

9. Sorra J, Franklin M, Streagle S. Medical office survey on patient safety culture. Rockville (MD): AHRQ; 2008 [cited 2021 Jan 11]. Available from: https://citeseerx.ist.psu.edu/viewdoc/ download?doi=10.1.1.474.9525\&rep=rep1\&type=pdf

10. Flores-González MT, Cruz-León A, Morales-Ramón F. Cultura de seguridad del paciente: percepción del personal de una unidad de medicina familiar en Tabasco, México. Rev Enferm Inst Mex Seguro Soc. 2019;27(1):14-22.

11. Astier-Peña MP, Torijano-Casalengua ML, Olivera-Cañadas G, SilvestreBusto C, Agra-Varela Y, Maderuelo-Fernández JA. Are Spanish primary care professionals aware of patient safety? Eur J Public Health. 2015;25(5):781-7.

12. Timm M, Rodrigues MC. Cross-cultural adaptation of safety culture tool for Primary Health Care. Acta Paul Enferm. 2016;29(1):6-37.

13. Webair HH, Al-assani SS, Al-haddad RH, Al-Shaeeb WH, Bin Selm MA, Alyamani AS. Assessment of patient safety culture in primary care setting, Al-Mukala, Yemen. BMC Fam Pract. 2015;16:136.

14. El Zoghbi M, Faroog S, Abulaban A, Taha H, Ajanaz S, Aljasmi J, et al. Improvement of the Patient Safety Culture in the Primary Health Care Corporation - Qatar. J Patient Saf. 2018 Apr 17. doi: 10.1097/ PTS.0000000000000489.

15. Raczkiewicz D, Owoc J, Krakowiak J, Rzemek C, Owoc A, Bojar I. Patient safety culture in Polish Primary Healthcare Centers. Int J Qual Health Care. 2019;31(8):G60-6.

16. Joanna Briggs Institute. The Joanna Briggs Institute reviewers' manual 2015: Methodology for JBI scoping reviews. Australia: Joanna Briggs Institute; 2015. [cited 2021 Mar 22]. Available from: https://nursing. Isuhsc.edu/JBI/docs/ReviewersManuals/Scoping-.pdf
17. Galvão TF, Pereira MG. Revisões sistemáticas da literatura: passos para sua elaboração. Epidemiol Serv Saúde. 2014;23(1):183-4.

18. Moher D, Liberati A, Tetzlaff J, Altman DG, The PRISMA Group. Preferred Reporting Items for Systematic Reviews and Meta-Analyses: the PRISMA Statement. PLoS Med. 2009;6(7):e1000097.

19. Hagopian B, Singer ME, Curry-Smith AC, Nottingham K, Hickner J. Better medical office safety culture is not associated with better scores on quality measures. J Patient Saf. 2012;8:15-21.

20. Mazurenko 0, Richter J, Kazley AS, Ford E. Examining medical office owners and clinicians perceptions on patient safety climate. J Patient Saf. 2018 Oct 10. doi: 10.1097/PTS.0000000000000540.

21. Hickner J, Smith SA, Yount N, Sorra J. Differing perceptions of safety culture across job roles in the ambulatory setting: analysis of the AHRQ Medical Office Survey on Patient Safety Culture. BMJ Qual Saf. 2014;25(8):588-94.

22. Pohlman KA, Carroll L, Hartling L, Tsuyuki R, Vohra S. Attitudes and opinions of doctors of chiropractic specializing in pediatric care toward patient safety: a cross-sectional survey. J Manip Physiol Ther. 2016;39(7):487-93.

23. Romero MP, González RB, Calvo MS. La cultura de seguridad del paciente en los médicos internos residentes de Medicina Familiar y Comunitaria de Galicia. Aten Primaria. 2017;49(6):343-50.

24. Yansane A, Lee JH, Hebballi N, Obadan-Udoh E, White J, Walji M, et al. Assessing the patient safety culture in dentistry. JDR Clin Trans Res. 2020;5(4):399-408.

25. Macedo LL, Silva AM, Silva JF, Haddad MC, Girotto E. A cultura em torno da segurança do paciente na atenção primária à saúde: distinções entre categorias profissionais. Trab Educ Saúde. 2020;18(1):e0023368.

26. Ramoni R, Walji MF, Tavares A, White J, Tokede 0, Vaderhobli R, et al. Open wide: looking into the safety culture of dental school clinics. J Dent Educ. 2014;78(5):745-56.

27. Macedo SM, Barboza AR, Borges F, Figueiredo KC, Peres AM, Assis F. Cultura de segurança do paciente: avaliação dos enfermeiros na atenção primária à saúde. Enferm Global. 2019;56:376-86.

28. RaimondiaDC,BernalaSC, OliveiraJL,MatsudaLM.Culturadesegurança do paciente na atenção primária à saúde: análise por categorias profissionais. Rev Gaúcha Enferm. 2019;40(Esp):e20180133.

29. Bodur, A, Filiz AE. A survey on patient safety culture in primary healthcare services in Turkey. Int J Qual Health C. 2009;21(5):348-55.

30. Tabrizchi N, Sedaghat M. The first study of patient safety culture in Iranian primary health centers. Acta Med Iran. 2012;50(7):505-10.

31. Paese F, Sasso GT. Patient safety culture in primary health care. Texto Contexto Nursing. 2013;22(2):302-10.

32. Marchon SG, Mendes Júnior WV, Pavão AL. Características dos eventos adversos na atenção primária à saúde do Brasil. Cad Saude Publica. 2015;31(1):2313-30.

33. Torijano-Casalengua ML, Olivera-Cañadas G, Astier-Peña MP, MaderueloFernández JA, Silvestre-Busto C. Validación de un cuestionario para evaluar la cultura de seguridad del paciente de los profesionales de atención primaria en España. Aten Primaria. 2013;45(1):21-37.

34. Silvestre-Busto C, Torijano-Casalengua ML, Olivera-Cañadas G, AstierPeña MP, Maderuelo-Fernández JA, Rubio-Aguado EA. Adaptación de la herramienta del cuestionario Medical Office Survey on Patient Safety Culture (MOSPSC). Rev Calid Asist. 2015;30(1):24-30.

35. Ramada-Rodilla JM, Serra-Pujadas C, Delclós-Clanchet GL. Adaptación cultural y validación de cuestionarios de salud: revisión y recomendaciones metodológicas. Salud Pública México. 2013;55(1):57-66. 